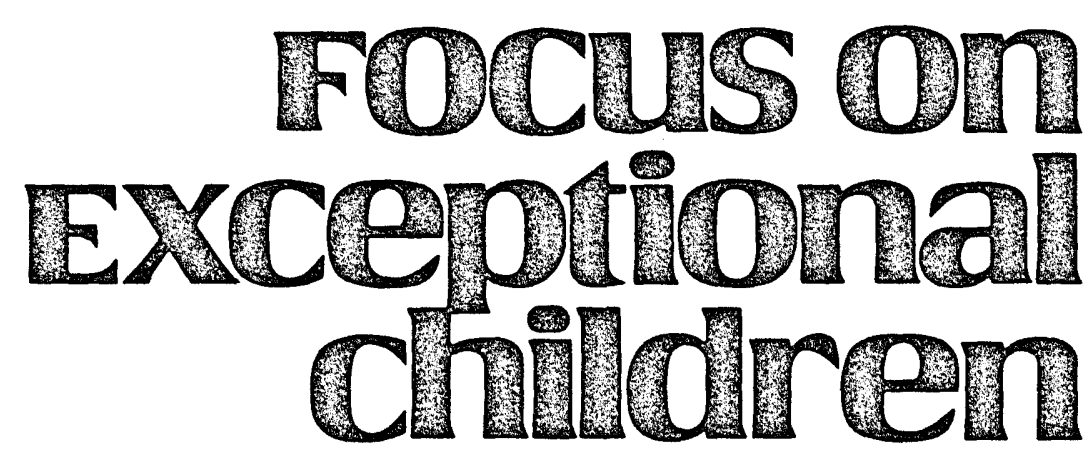

\title{
An Analysis of One of the Cornerstones Of the Regular Education Initiative
}

\author{
M. L. Anderegg and Glenn A. Vergason
}

In recent years there have been calls to improve the interfacing of regular education and special education (Greenburg, 1987). Some of the advocates have proposed a merging of special education and regular education into one system (Lilly, 1986; Stainback \& Stainback, 1984; Will, 1984, 1985).

It is hard to look at the special education delivery systems and the legal concept of least restrictive environment and not to see that special and regular education are two parts of a system that must have a close working relationship and be more unified than they have been before. The purpose of this article, however, is not to debate the merits of the regular education initiative, or the interfacing of regular and special education. Instead we will look at one of its cornerstones, analyze the problems inherent in its application, and express our concerns about its widespread implementation.

\section{BACKGROUND}

As Assistant Secretary of Education, Madeline Will has been the torch bearer for this movement. Will $(1984,1985)$ articulated the need for regular education and special education to be combined, with the local school principal being empowered as the instructional leader. Robson (in Greenburg, 1987) has suggested that this arrangement already has been approached in the job roles of principals.

Will introduced her proposal for the Regular Education Initiative in speeches and in journal articles. Further, she established policy, including a National Task Force to Advance the Regular Education Initiative, to facilitate the interfacing of special education and regular education. Among its members is Margaret Wang. Although Will is generally considered to be the initiator of the concept, the influence of Wang and her associates, as revealed in the literature, was paramount in shaping Will's thinking. In fact, Wang's Adaptive Learning Environment Model (ALEM) is central to Will's regular education initiative movement (Wang \& Reynolds, 1985). Development of the model was funded by both the Office of Special Education and Rehabilitation and the National Follow Through Program (dealing with the education of disadvantaged children).

Drs. Anderegg and Vergason are affiliated with the Department of Special Education, Georgia State University.

(C) Love Publishing Company, 1988. 


\section{WHAT IS ALEM?}

Wang's model has been described as "the case of successful merger of special and general education services in regular classes" (Wang \& Reynolds, 1985, p. 498). ALEM represents possibly the most extensive synthesis and operationalization of the literature concerning effective teaching to date. It has the potential for economy and consistency in implementation, though both of these potentials are compromised (as discussed later).

ALEM appears to synthesize and operationalize that body of work known as effective teaching-reaching back to Bloom's (1976) work. As Wang (1970) stated:

The basic elements [of this model] include (a) detailed sequences of behavioral objectives which define the abilities that each pupil is to acquire, (b) study materials that are largely self-instructional in nature, to teach each objective, (c) a testing program for placing each pupil at the proper point in the curriculum sequence and for monitoring his progress, and (d) classroom management procedures that permit each pupil to proceed at a rate best suited to his needs. (p. 36)

\section{FOcus on Exceptional children}

FOCUS ON EXCEPTIONAL CHILDREN (ISSN0015-511X) (USPS 203-360) is published monthly except June, July, and August as a service to teachers, special educators, curriculum specialists, administrators, and those concerned with the special education of exceptional children. This publication is annotated and indexed by the ERIC Clearinghouse on Handicapped and Gifted Children for publication in the monthly Current Index to Journals in Education (CIJE) and the quarterly index, Exceptional Child Education Resources (ECER). It is also available in microform from Xerox University Microfilm, Ann Arbor, MI. Subscription rates: Individuals, $\$ 24$ per year; institutions, $\$ 30$ per year. Copyright (C) 1988, Love Publishing Company. All rights reserved. Reporduction in whole or part without written permission is prohibited. Printed in the United States of America. Second class postage is paid at Denver, Colorado.

POSTMASTER: Send address changes to:

Love Publishing Company

Executive and Editorial Office

1777 South Bellaire Street

Denver, Colorado 80222

Telephone (303) 757-2579

EDITORIAL BOARD

Edward L. Meyen

University of Kansas

Richard J. Whelan

Glenn A. Vergason

Georgia State University

University of Kansas Medical Center

Stanley F. Love Publisher

Carolyn Acheson Senior Editor
In the ALEM, instruction is based on behavioral objectives employing self-instructional materials and a prescribed classroom management program.

Application of the model appears to contribute substantially to change in behaviors of both teachers and students, which are directly related to achievement in average and above-average learners. But serious problems in development of the model should cause concern to those who would evaluate its possible adaptation as a vehicle to accomplish the aims of the Regular Education Initiative.

\section{PROBLEMS WITH THE ALEM RESEARCH}

Quite possibly, the ALEM in total or in part may provide some effective mainstreaming technology. Elements such as decreased teacher variability, for example, are already described as effective teaching and do not demand specialized reorganization of delivery systems. In the model, specific procedures are prescribed for teacher interaction with both students and paraprofessionals. The research examined herein, however, does not verify any additional contribution from these procedures.

The model itself is a consistent, implementable model of effective teaching in a regular classroom setting with average learners through second grade. Average learners are considered to be students who do not meet legislative guidelines as handicapped no matter how many other learning inhibitory factors may exist for them. The processes employed in the ALEM, such as the influence of self-instructional materials and self-selection in activities, are consistent with available literature on average learners. The results substantiate their usefulness in the kinds of behavior changes labeled learning. Nevertheless, at least 10 problems or problem areas can be delineated in regard to the ALEM research.

1. The ALEM researchers have not demonstrated use with learners who, under PL 94-142 or subsequent legislation, are called "handicapped." Descriptions of the populations with whom the ALEM has been applied are clear on only a few points: The ALEM produces differences in achievement results and behavior patterns in inner-city children, black underachievers, economically deprived children, and those who are gifted. The extent of handicapped children's involvement, if any, in these studies is unclear.

Reference is made to children who were "similar" to children with learning disabilities in a study in which the population included twice as many gifted as "low achievers" (Wang, 1981, p. 205). The presence and number of gifted students in the sample could well account for the differences. 
The dissimilarities between the subjects and learning disabled children, however, would have provided more pertinent information. Funding problems with the agency funding special education programs resulted (Wang \& Reynolds, 1985 , p. 500), and these persist to the most current implementation reported (Bott, 1987).

One study (Wang, Peverly, \& Randolph, 1984) reported "a total of 69 mainstreamed students" (p. 23) spread over 26 mainstream classrooms located in five different schools. Class enrollments ranged from 21 to 31 students. We are told that these "mainstreamed students" included educable mentally retarded, learning disabled, and socially/emotionally disturbed students. We are not told by what or whose criteria those designations were made or whether they met eligibility criteria for that state. Because the details of the criteria are missing, it is impossible to determine whether to accept these results as applicable or generalizable to known handicapped groups.

2. The ALEM researchers have not investigated setting as a variable and should not assume the settings in which the research took place to be more effective than resource or other delivery models. Wang commented on this deficit twice (Wang, 1970, 1981). In the 1983 application the variables were implementability, student behaviors during learning, student perception of self-responsibility for learning, and staff development (Wang \& Gennari, 1983).

3. The ALEM researchers have not investigated the variance gained or maintained in grades past the second grade (concrete level of learning). The task demands of learning change as the level of learning progresses from concrete to abstract levels. Those changes in task demands and learning levels are the basis for the differences in pedagogy among the various certification levels of teachers in general education.

At the Teacher Education Division (TED) of the Council for Exceptional Children Conference, Wang (1987a) noted that "some" data existed for fourth grade, "quite a lot" for the upper levels of high school, and "a little" for middle school. She admitted that none of these data had been published and did not elaborate on the results. Certainly if data exist, this information should be in the literature so professionals can make their judgment about the suitability of a model that might well be universally applied.

4. The ALEM researchers have not investigated the variance accounted for by level of task difficulty, certification of teachers involved, or other confounding variables. Wang is not naive concerning the effect of confounding variables.
In the development of the current ALEM model, Wang and her associates investigated the effects of hierarchical math objectives (Wang, Resnick, \& Boozer, 1971); the effects of teachers' questions on children's responses (Wang, 1973); the effects of passive learning styles on rate of learning (Wang \& Stiles, 1976); the effects of perceptions of self-responsibility for school learning and the effects of student locus of control on learning (Wang \& Stiles, 1976); peer tutoring (Fogarty \& Wang, 1982); and self-instruction (Wang \& Peverly, 1986).

Concerning the variable of task difficulty, for example, the age group that Wang studied was engaged in acquisition of basic foundational skills that include high drill frequency. These skills lend themselves well to self-instructional materials. This was true in the ALEM application as well. "Teachers tended to assign more review tasks and smaller tasks (e.g., fewer workbook pages) to low achievement expectancy students than to students in the other two groups" (Levine \& Wang, 1983, p. 241). As noted earlier, task demands in school later become more complex and of a different nature. These changes in task demands create serious problems in assuming the effectiveness of the model beyond the second-grade level.

5. The ALEM researchers have not provided any data on the amount of variance provided within the implementation of the ALEM by the self-instructional materials used. Because the self-instructional materials were important enough to the model that they were specified in its completed implementations, the variance contributed by the materials should be analyzed. On the other hand, if the materials are not that important, they need not be specified in implementations.

Again, the ALEM developer is not uninformed about the effect of materials on learning. In earlier work Wang (1970) investigated rate of learning. The conclusion was that rate of learning is not consistent over all materials: "It may be concluded that rate of learning is specific to a given task and is not a general factor characterizing student performance in all learning situations" (p. 45).

6. The ALEM researchers have not used the data gathered in the studies in a way consistent with the best use and practice of statistical data analysis. Correlational relationships are not defensible as a basis for causal statements (Wang \& Walberg, 1983b). Regression techniques were sometimes used inappropriately (Wang \& Walberg, 1983b) and at other times were not used when they would have been appropriate (Levine \& Wang, 1983; Wang \& Stiles, 1976). 
Use of regression to develop a causal model is not the best use of this statistic. Although regression has been called the workhorse of statistics, it is not appropriate for use in making causal statements. Factor analysis (a more appropriate statistic for developing models) is not mentioned. Canonical regression had been used to study rate of learning during the earliest states of the model's evolution (Wang, 1970).

A later article describing the essence of the fully implemented model made causal statements based on regression results (Wang \& Walberg, 1983b). In that article Mosteller and Tukey (1977) were referred to-but inappropriately. Mosteller and Tukey list three ideas required to support causality: consistency, responsiveness, and mechanism (p. 260). The observational data from the ALEM implementation do not provide substantiation of any of the three ideas required to support causality.

7. The ALEM researchers have not employed control or contrast groups as part of the a priori design. Despite Wang's assertion that "the purpose was to examine the ALEM's impact on student achievement and not to make cross-site comparisons" (Wang \& Birch, 1984, p. 395), the ALEM has been posited, without benefit of either a control or contrast group, as a definitive model of successful mainstreaming of mildly handicapped children (Wang \& Walberg, 1983a), and that is the way it is applied in the regular education initiative.

In the one study two possibly post hoc comparison groups are mentioned, but no data are offered concerning task length or difficulty. The importance of the effect of task length and difficulty were mentioned by Levine and Wang (1983). This deficit becomes more important because in publications beyond the original reports of the data, the details of these comparison groups increase in prominence.

8. The ALEM researchers have not utilized adequate samples. One would expect of such a comprehensive program an equally comprehensive body of observational data. Such is not the case, especially when the data are calculated into per-student, per-classroom segments. The manner in which the data were reported makes that calculation possible in only one application (Wang, 1981).

An examination of the reported 1981 observation data shows an average of less than 5 minutes per student per year in observation time. Calculations of the average observation time per classroom resulted in 1.7 hours per classroom per year. The reported interrater reliability (in 80 's) is not quite as impressive when the total reported observation times are broken down into per-student, per-classroom segments. Less than 5 minutes of observation of a student each year can hardly yield sufficient data to draw any defensible conclusions about interrater reliability, much less about that student's daily activities.

9. The ALEM has not demonstrated that the progress of students in the sample used is any different than could be expected under less intrusive applications of effective teaching practices. The 1983 study reported that the students' relative positions on achievement "at the beginning of the school year remained unchanged at the end of the year" (Levine \& Wang, 1983, p. 242). This seems to indicate that student achievement of the population used, in terms of relationship to the average population, may be similar to student achievement under other regular education programs regardless of the effectiveness of the teaching strategies used.

A more detailed evaluation could not be made because beginning and ending data were not consistently described. The beginning data were described by chronological age. The ending data were presented in terms of grade levels without any mention of the number of students who might previously have been retained.

10. The ALEM's developer has used unequivalent comparisons, which have the effect of inflating the findings. Although it is reported that "recommendation" for exit from special education certification was at a $30 \%$ level, no exits were reported. The comparison made between actual decertification rate of special education students in resource rooms and the recommendations of the ALEM researchers is invalid because it compares two very different samples.

Decertification is not possible unless actual certification precedes it. Certification for special education services occurs only when the student has been referred, tested, and certified as handicapped. Certainly if certification of the subjects had existed at the beginning of the study, such an important followup should have been implemented regardless of whether the final rate of exit was in agreement with the recommendations. This would have been especially critical when funding from agencies associated with the handicapped was in jeopardy (Wang \& Reynolds, 1985, p. 500).

Each of these ten problems, alone, would produce concern for the risks involved in widespread implementation of the model. Together, the problems produce valid concerns that must be addressed.

\section{CONCERNS}

Although the ALEM represents an extensive body of research, the problems described give rise to serious concerns. 
The first of these relates to generalizability. How can the findings be generalized to the mildly handicapped without additional work? What assurances can be drawn from the current body of literature of ALEM's implementation that a benefit is to be derived for the mildly handicapped? If the ALEM does not change the handicapped learner's ranking on achievement, how can it be called an improvement in educational services? Is it not rather a housekeeping improvement for general education? How can no reported decertifications (the stituation with the ALEM) be considered superior to an actual rate of decertification (whatever the resource room percentages)?

The second concern arises from the level of learning addressed in the ALEM. What effect does the cognitive shift from concrete to abstract in learning have on the model's implementation and results? Is it not reasonable to wonder if implementation of materials and methodologies consistent with lower levels of learning might cause earlier plateaus in achievement than the current fifth-grade plateaus reported by some researchers (Deshler, Schumaker, Alley, Warner, \& Clark, 1982; Sheinker, Sheinker, \& Stevens, 1984)?

A third concern involves personnel and funding. If implemented, how extensive will be the additional training required of teachers and paraprofessionals? Will the educators involved accept the changes? How will the school systems provide the training? Outside of a university research setting, who will fund that training, and how? For less affluent school systems, the loss of federal funds similar to those mentioned by a representative of the Kentucky implementation (Bott, 1987) might spell disaster. Who will regulate the training and the implementation? Surely, monitoring for widespread implementation of such an extensive program would not be dependent on the less than 2 hours' observation per year reported in the current literature on the model.

Would special education funds be comingled with general education funds and spread over a much broader base including disadvantaged and slow learners, with the result being fewer services for all? By what criteria would such funding be allocated? Will parents who fought so hard for services for their handicapped children tolerate such dilution of services? Is it legal without broad changes in PL 94-142?

A fourth concern revolves around matters of practical application. Which current certification group-regular classroom teachers or special education teachers-would implement the model? Would new certification groups be necessary to implement this model?

How specialized would the school setting have to be to accommodate the model's requirements? Application in a university research setting, such as that in which much of
Wang's research occurred, with the special advantages incumbent to it, is surely different from applications in the public sector. What are those differences? What cost factors and other complications would be involved? How extensive are the record-keeping requirements? Would implementation require a mainframe computer to account for personnel hours across categorical lines as was required in a similar crosscategorical program (Felix, Hertlein, McKenna, \& Rayborn, 1987)? Or would the record keeping require additional recording by educators? What response would general educators have toward the increased paperwork?

These concerns have to be addressed in ways that are consistent with the best use and practice of research design and methodology. Resolution of these concerns cannot be based on the current literature available on the ALEM because of the many problems inherent in that literature.

In view of these problems and concerns, the conclusion one must draw should focus on the original intent of the regular education initiative. The original goal was not just to replace current practice with something new in the regular classroom setting but, instead, to improve interaction between two parts of the same system.

\section{CONCLUSIONS}

The pull-out programs, which have been so widely criticized by proponents of the regular education initiative, are a part of the continuum of services designed to address the heterogeneity of the mildly handicapped population. Under the regular education initiative that continuum would be shorted to exclude pull-out programs intended to provide services to increase the independence of the learner in a variety of settings. Though criticisms of pull-out programs are widespread, the major concern of a lack of curriculum in the pull-out programs is never addressed in either the regular education initiative or the ALEM.

The ALEM model may improve teaching practices in the regular classroom at the early elementary school level. In the years for which demonstration has been provided, it did improve the lot of the unserved and unclassified or nonhandicapped underachievers. Certainly the unserved and unclassified are due their opportunity to learn. But there exist less intrusive ways of providing that opportunity without disrupting or destroying part of the overall system that now exists, and without risking alienation between two parts of the same system. Those less intrusive ways are funded (as ALEM developers well know) through the National Follow-Through Program.

The ALEM fails to address the problem of curricular changes in resource settings needed to provide the teacher 
consultation and compensatory skills and strategy training that handicapped learners require to function as independent learners. The ALEM may provide needed remediation in the regular classroom setting, but less intrusive measures, such as effective teaching practices and curriculum-based assessment (Deno \& Fuchs, 1987), are available. The less intrusive measures offer the additional benefits of preserving funding for handicapped learners.

The two alternative measures also require less paperwork than the ALEM and are more amenable to improving the total system from a standpoint of instructional leadership. Paperwork already has been identified as the most frequent factor in attrition for some special education teachers (Dangel, Bunch, \& Coopman, 1987). Should a new category of teachers, neither special nor general education, be formed for whom the paperwork would become the most common attrition factor?

Perhaps the single most important contribution that might be elicited from the ALEM is the provision of a standardized model of teacher training at the preservice level. But even that contribution would be compromised unless further work would be invested in the model. First it must be demonstrated that the teacher behaviors prescribed in the ALEM do, in fact, significantly improve the rate of learning of every group of learners. Then, perhaps, those behaviors demonstrated could become the nucleus of a set of objectives for teacher training programs.

A regular education initiative, if it is to succeed, will come from a consortium of general and special educators in which collaboration occurs among equals who share a common goal. Elitist attitudes toward any program doom collaboration. Leiberman's "uninvited bride" (Leiberman, 1985) provides a colorful analogy of the current regular education initiative. Leiberman likened special educators' planning of a regular education initiative to an aggressive bridegroom who plans a wedding assuming the bride will agree to participate.

Much more research with larger populations that are clearly identifiable as including handicapped learners, with better methodology and improved design components, is necessary. From those results, a more informed and less intuitive implementation of the ALEM might be possible.

We hope this analysis of studies related to the ALEM will allow special and regular educators to better evaluate the pros and cons of the regular education initiative if overreliance is being placed on this model in developing educational programs.

\section{REFERENCES}

Bloom, B.S. (1976). Human characteristics and school learning. New York: McGraw-Hill.

Bott, C. (1987, November). Model programs integrating general and special education: Reports and reactions. Remarks from the Teacher Education Division of the Council for Exceptional Children Tenth Annual Conference.

Dangel, H.L., Bunch, A.W., \& Coopman, M.P. (1987). Attrition among teachers of learning disabled students. Learning Disabilities Focus, 2 , $80-86$.

Deno, S., \& Fuchs, L. (1987). Developing curriculum-based measurement systems for data-based special education problem solving. Focus on Exceptional Children, 19, 1-16.

Deshler, D.D., Schumaker, J.B., Alley, G.R., Warner, M.M., \& Clark, F.L. (1982). Learning disabilities in adolescent and young adult populations: Research implications. Focus on Exceptional Children, 15, $1-12$.

Felix, N., Hertlein, F., McKenna, D., \& Rayborn, R. (1987). Combining categorical program services can make a major difference. Phi Delta Kappan, 68, 787-788.

Fogarty, J.L., \& Wang, M.C. (1982). An investigation of the cross-age peer tutoring process: Some implications for instructional design and motivation. Elementary School Journal, 82, 451-469.

Greenburg, D.E. (1987). A special educator's perspective on interfacing special and general education: A review for administrators. Reston, VA: Council for Exceptional Children.

Leiberman, L.M. (1985). Special education and regular education: A merger made in heaven. Exceptional Children, 51, 513-516.

Levine, J.M., \& Wang, M.C. (1983). Development and consequences of students' sense of personal control. Teacher and student perceptions: Implications for learning (pp. 213-247). Hillsdale, NJ: Lawrence Erlbaum Associates.

Lilly, M.S. (1986). The relationship between general and special education: A new face on an old issue. Counterpoint, 6(1), 10.

Mosteller, F., \& Tukey, J.W. (1977). Regression for fitting data analysis and regressions, Reading, MA: Addison-Wesley.

Sheinker, A., Sheinker, J.M., \& Stevens, L.J. (1984). Cognitive strategies for teaching the mildly handicapped. Focus on Exceptional Children, $17,1-16$

Stainback, W., \& Stainback, S. (1984). A rationale for the merger of special education and regular education. Exceptional Children, 51, $102-111$.

Wang, M.C. (1970). Use of the canonical correlation analysis in an investigation of pupils' rate of learning in school. Journal of Educational Research, 64, 35-45.

Wang, M.C. (1973). Verbal prompting and young children's descriptive language. Language Science, 5, 27-31.

Wang, M.C. (1981). Mainstreaming exceptional children: Some instructional design and implementation considerations. Elementary School Journal, 81, 195-221.

Wang, M.C. (1987a, November). Model programs integrating general and special education: Reports and reactions. Remarks from the Teacher Education Division of the Council for Exceptional Children Tenth Annual Conference.

Wang, M.C. (1987b). Toward achieving educational excellence for all students: Program design and student outcomes. Remedial \& Special Education, 8, 25-34.

Wang, M.C., \& Birch, J.W. (1984). Comparison of a full-time mainstreaming program and a resource room approach. Exceptional Children, 51, 33-40.

Wang, M.C., \& Gennari, P. (1983). Analysis of the design, implementation, and effects of a data-based staff development program. Teacher Education \& Special Education, 6, 211-226. 
Wang, M.C., \& Peverly, S.T. (1986). The self-instructive process in classroom learning contexts. Contemporary Educational Psychology, $11,370-404$.

Wang, M.C., Peverly, S.T., \& Randolph, R. (1984). An investigation of the implementation and effects of a full-time mainstreaming program. Remedial \& Special Education, 5, 21-32.

Wang, M.C., Resnick, L.B., \& Boozer, R.F. (1971). The sequence of development of some early mathematics behaviors. Child Development, 42, 1767-1778.

Wang, M.C., \& Reynolds, M.C. (1985). Avoiding the "catch 22" in special education reform. Exceptional Children, 51, 497-502.

Wang, M.C. \& Stiles, B. (1976). An investigation of children's concept of self-responsibility for their school learning. American Educational Research Journal, 13, 159-179.

Wang, M.C., \& Walberg, H.J. (1983a). Adaptive instruction and classroom time. American Educational Research Journal, 20, 601-616.

Wang, M.C. \& Walberg, H.J. (1983b). Evaluating educational programs: An integrative, causal-modeling approach. Educational Evaluation \& Policy Analysis, 5, 347-366.

Will, M. (1984). Let us pause and reflect-but not too long. Exceptional Children, 49, 246-252.

Will, M. (1985, December). Educating children with learning problems: A shared responsibility. Remarks before the Wingspread Conference on the Education of Children with Special Needs, Racine, WI.

\section{Professional update}

\section{NEW BOOKS}

\section{Down Syndrome: \\ A Resource Handbook \\ by Carol Tingey}

Here is a comprehensive paperback written most competently for those who are involved with Down syndrome individuals. It is particularly helpful for parents, families, educators, and service providers. Contributors include teachers, professors, physicians, occupational and physical therapists, administrators, special education personnel, child development experts, and others.

The book is organized into four major sections-medical issues, family, early development, and education and community activities. It covers physical characteristics, medical considerations, counseling, facilitating speech and language, school experiences, employment training, recreation and activities, and more.

Other features include glossary, tabular material, growth charts, and delightful illustrations. This is a book that anyone who interacts with Down syndrome persons should not be without.

College-Hill Press, San Diego, is the publisher of this 200-page book.

\section{Children with Epilepsy: \\ A Parent's Guide \\ Edited by Helen Reisner}

More than 1.5 million children in the U.S. under age 18 have epilepsy. This new book, written by doctors, therapists, educators, lawyers, and parents, offers a complete look at epilepsy. Topics range from physical considerations to emotional adjustment to legal ramifications. It is most useful for parents and families, but educators would benefit from the thorough discussion of the "whats and hows" of dealing with those who have this seizure disorder.

The book begins with a definition of the condition, followed by a discussion of adjustment and helping the child develop self-esteem, and concludes with chapters on special education needs and legal rights. It includes a comprehensive reading list, resource guide, and glossary. It is visually appealing, with photographs and vignettes.

The publisher of this 316-page paperback is Woodbine House, Kensington, MD.

$$
* * *
$$

\section{Effective Instructional Strategies \\ for Exceptional Children}

Edited by Edward L. Meyen, Glenn A. Vergason, and Richard J. Whelan

The editorial board members of Focus on Exceptional Children have compiled a series of articles from this periodical, plus others relating to effective instruction, into a book that will be of particular interest for college courses dealing with curriculum. The book has three major sections-instructional organization, teaching presentation, and assessment strategies.

Among the topics covered are classroom management, cognitive-behavioral training, a self-control curriculum, peer tutoring, guidelines for assessment, measuring adaptive behavior, CBM systems, and more. This collection, representing recent research and practices related to effectiveness in teaching, is good news for those who want to teach and apply the most current, proven methods advocated in education today.

This 520-page paperback is published by Love Publishing Company, Denver. 
FOCLS OR

Excepritional

Chimedren

\section{Number of Learning Disabled Children 3 - 21 Years Old Receiving Related Services During the 1984-85 School Year}

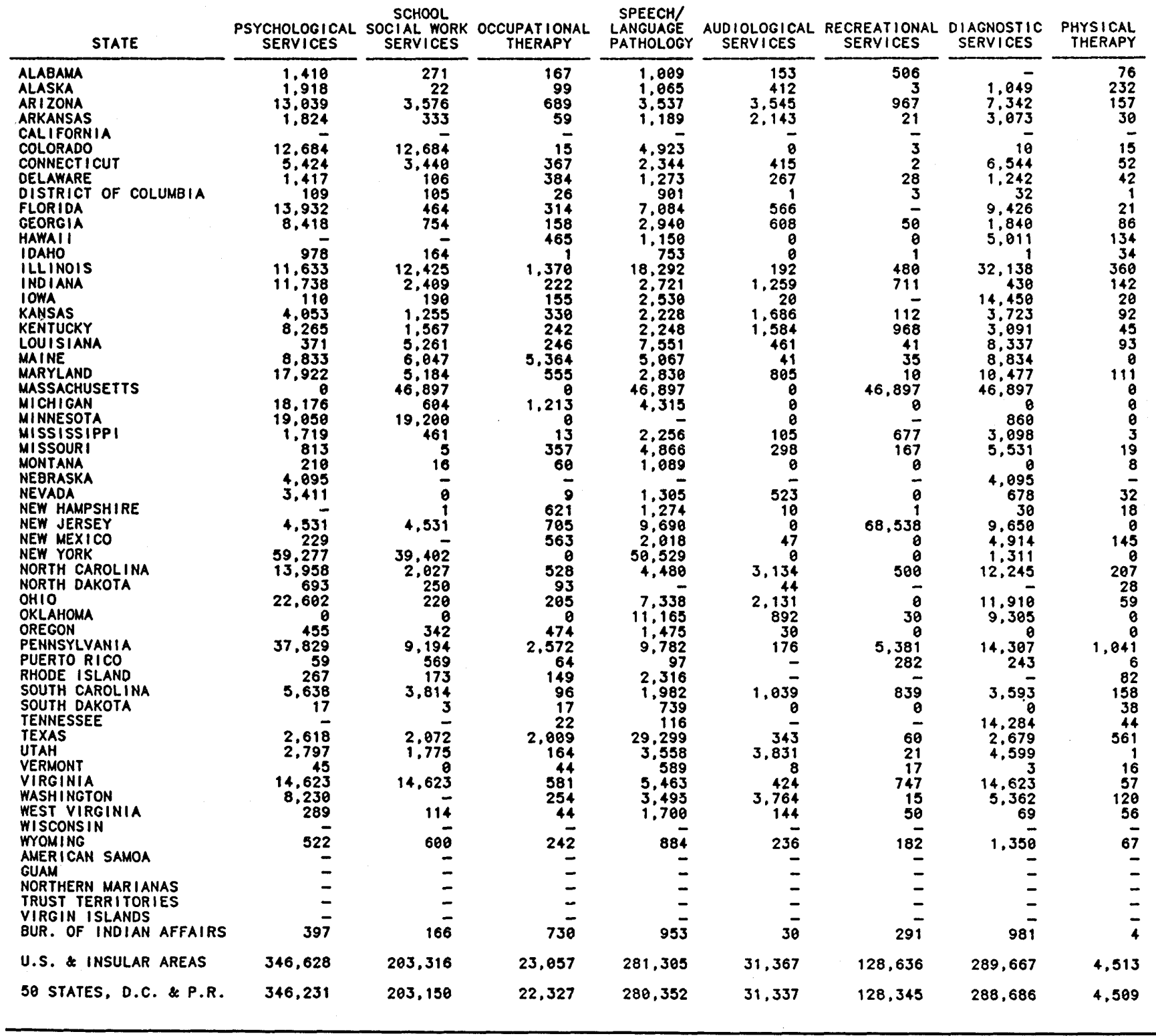

From Ninth Annual Report to Congress on the Implementation of the Education of the Handicapped Act, 1987, Washington, DC: U.S. Department of Education, p. E-25. 